\title{
Qualitative and quantitative determination of resistance of twenty two Malaysian commercial timbers through subterranean termite feeding behavior
}

\begin{abstract}
The durability of wood, or the natural resistance of wood against termites, is an extremely variable property. The durability of 22 Malaysian commercial timber species has been reviewed based on the European Standard 350-1 (1994) (laboratory trials) of the Heartwood of mature timbers harvested from the natural forest. Based on this, the European standard EN118 (2005) was used for termites test. Coptotermes curvignathus was introduced to different wood species in controlled conditions for 8 weeks. The efficacy in wood degradation was calculated based on average of weight loss and visual rating of each timber species. The results showed that 2 timber species fall under durable and 3 species under moderately durable while the other 17 species under susceptible class
\end{abstract}

Keywords: deterioration, durability, malaysian timbers, en118, subterranean termites
Volume I Issue 2 - 2017

\author{
K Roszaini,' U Salmiah,' S Rahim,' L \\ Shahlinney,' AR Nor Azried,' K Baharudin,' \\ TO Mohd Adawi, ${ }^{2}$ Kum PS, ${ }^{3}$ A Hamidah ${ }^{4}$ \\ 'Forest Research Institute Malaysia (FRIM), Malaysia \\ 2Malaysian Timber Industry Board (MTIB),Wilayah Persekutuan \\ Kuala Lumpur, Malaysia \\ ${ }^{3}$ Malaysian Wood Industries Association, Wilayah Persekutuan \\ Kuala Lumpur, Malaysia \\ ${ }^{4}$ Malaysian Timber Council,Wilayah Persekutuan Kuala Lumpur, \\ Malaysia
}

\begin{abstract}
Correspondence: Roszaini Kadir, Forest Research Institute of Malaysia (FRIM), 52109 Kepong, Selangor Darul Ehsan, Malaysia, Tel 00603-62797410,Email roszaini@frim.gov.my
\end{abstract}

Received: July 10, 2017 | Published: November 03, 2017

\section{Highlights}

a. Twenty two Malaysian commercial timber species were determining their natural durability against termites based on European Standard EN350:1994.

b. Only 5 Malaysian timber species are better than Pinus spp. i.e. 2 species fall under durable class and 3 species under moderately durable.

c. Certain treatments are needed especially to susceptible timber species in order to ensure a longer service life of the wood.

\section{Introduction}

As defined in BS EN 350-1, ${ }^{1}$ natural durability is 'the inherent resistance of wood to attack by wood destroying organisms'. Eaton $\& \mathrm{Hale}^{2}$ defined natural durability or decay resistance as the ability of the Heartwood of any wood species to resist decay. Normally, natural durability is measured by exposing the wood to biological agents such as termites, beetles, fungi and marine borers (e.g., ${ }^{3,4}$ While the natural durability of Heartwood is important for situations either to be used partially or fully exposed to the weather, sapwood is always regarded as having low natural durability (perishable or non-durable) except if treated. Certain types of timber are noted for their marked resistance to deterioration and are commonly used as untreated material. In contrast, non-durable timbers generally require preservative treatment if they are to be used in exposed conditions, adding significantly to their cost.

A number of factors influence the durability of a timber, including wood density, tree age, and growing location. The wood resistance, especially against fungal attack also could be increased by the presence of lignin, which, surrounding the crystalline cellulose and even though only $0.03-0.1 \%$ of nitrogen content in the wood, to some extent contributed to the natural resistance of the wood. ${ }^{5}$ However, the most important factor is the extractives within the wood itself, which are formed after the sapwood is transformed into Heartwood. ${ }^{6}$ It's having long been recognized as key features that impart natural durability in the Heartwood of certain wood species. ${ }^{7,8}$

Preliminary studies have found that Malaysian timbers are categorized as not durable based on graveyard test, but durable when they are determined by EN 350-1. ${ }^{1}$ Malaysia suffered a loss in terms of price premiums as most Malaysian timbers are placed in Grade 4 and 5 based on earlier studies which indicated that $80 \%$ of the wood has been categorized as moderately durable and not durable by the graveyard test. Low natural durability of the wood could shorten the service life of a structure or even lead to structural strength failure, when the surrounding conditions e.g. climate, are stimulating growth of fungi in the wooden members. In that case it is important to know the durability of timber in order to minimize the cost of building constructions. Keeping the durability grades meaningful, it might be necessary to define a laboratory test with regard to insect/termite which could be used to compare the natural durability of wood species relative to each other.

As mentioned by Silva et al. ${ }^{9}$ one of the most limiting factors for the commercial utilization of wood is because of its low resistance to termites and fungi. This study aims to determine the natural durability of Malaysian timbers upon exposure to damaging agents such as termites as stipulated in EN 350-1. ${ }^{1}$ A total of twenty two Malaysian timber species has been identified to undergo a stress test (durability) of wood in laboratory condition trials with Pinus sp. include as reference timbers. Subterranean termite; Coptotermes curvignathus which is among the aggressive species in Malaysia will be used. 


\section{Materials and methods}

\section{Raw materials}

The wood species used in this study are the most commercial Malaysian wood species which were extracted from the Terengganu forest reserve. Southern yellow pine; Pinus spp. was used as a control block as indicated in European Standard EN118. ${ }^{10}$ All wood species from basal portion of three trees were cut into wood blocks of the size of $(50 \times 50 \times 10 \mathrm{~mm})$ (radius $x$ tangential $x$ longitudinal). Relevant wood characteristics of these Malaysian timbers are described in Table 1.

\section{Bioassay test against termites}

Ten (10) replicates of wood blocks used for each wood species. Testing method adopted was European Standard EN118 ${ }^{10}$ using Asian subterranean termites (Coptotermes curvignathus Holmgren (Isoptera: Rhinotermitidae) collected from active field colonies at the Forest Research Institute Malaysia (FRIM) campus using a method described before. ${ }^{11}$

Table I Wood characteristic and properties of 22 Malaysian commercial timbers and Pinus spp. ${ }^{14,35-38}$

\begin{tabular}{|c|c|c|c|c|c|c|}
\hline Species & Local name & Basic density $\left(\mathrm{kgm}^{-3}\right)$ & $\begin{array}{l}\text { Strength } \\
\text { group }\end{array}$ & $\begin{array}{l}\text { Sapwood \& } \\
\text { heartwood defined? }\end{array}$ & $\begin{array}{l}\text { Natural } \\
\text { durability }\end{array}$ & $\begin{array}{l}\text { Treatability } \\
\text { with cca }\end{array}$ \\
\hline A. Mangium & Akasia (LHW) & $290-580$ & C & Yes & ND & Easy \\
\hline O. Sumatrana & Binuang (LHW) & $270-465 \mathrm{~kg}$ & $\mathrm{D}$ & Yes & ND & Easy \\
\hline C.Arborescens & Geronggang (LHW) & $350-610$ & $\mathrm{D}$ & Yes & ND & Easy \\
\hline Parashorea spp. & Gerutu (LHW) & $640-880$ & C & Yes & ND & Difficult \\
\hline D. Costulata & Jelutong (LHW) & $420-500$ & $\mathrm{D}$ & No & ND & Very easy \\
\hline D. Aromatica & Kapur (MHW) & $575-815$ & B & Yes & $\mathrm{D}$ & Difficult \\
\hline Canarium spp. & Kedondong (LHW) & $495-980$ & C & Poor & ND & Difficult \\
\hline C. Malaccencis & Kekatong (HHW) & $880-1,155$ & A & Poor & MD & Difficult \\
\hline Syzigium sp. & Kelat (MHW) & $495-1,010$ & B & Poor & MD & Difficult \\
\hline Artocarpus sp. & Keledang (MHW) & $500-945$ & B & Yes & MD & Easy \\
\hline N. Cadamba & Kelempayan (LHW) & $290-465$ & $\mathrm{D}$ & No & ND & Easy \\
\hline Dipterocarpus spp. & Keruing (MHW) & $690-945$ & $A \& B$ & Yes & MD & Very easy \\
\hline S. Borneensis & Kulim (MHW) & $640-975$ & B & Yes & MD & Easy \\
\hline M. indica & Machang (LHW) & $545-610$ & C & Poor & MD & Very easy \\
\hline Cinnamomum spp. & Medang (LHW) & $350-880$ & C & Yes & ND & Difficult \\
\hline Heritiera spp. & Mengkulang (MHW) & $625-895$ & B & Yes & ND & Easy \\
\hline S. Platyclados & Meranti bukit (LHW) & $505-870$ & C & Poor & MD & Easy \\
\hline S. Parvifolia & Meranti sarang punai (LHW) & $385-755$ & C & Yes & ND & Easy \\
\hline Anisoptera sp. & Mersawa (LHW) & $515-735$ & C & No & MD & Difficult \\
\hline P.Velutinus & Pelong (LHW) & $480-835$ & $\mathrm{D}$ & No & MD & Difficult \\
\hline E. Malaccense & Sesendok (LHW) & $305-655$ & $\mathrm{D}$ & No & ND & Very easy \\
\hline F. Fragrans & Tembusu (HHW) & $640-1,075$ & B & No & $\mathrm{D}$ & Difficult \\
\hline Pinus spp. & Southern Yellow Pine & $375-585$ & $\mathrm{D}$ & No & ND & Easy \\
\hline
\end{tabular}

Density class is based on strength and durability. ${ }^{36} \mathrm{HHW}$-heavy hardwood, MHW-medium hardwood, LHW-light hardwood. Durability rating: ${ }^{14} \mathrm{ND}$-nondurable (<2years), MD-moderately durable (2-5years), D-durable (>5years). CCA treatability: ${ }^{39}$ Very easy (>320 lit $\left./ \mathrm{m}^{3}\right)$, East $\left(240-320 \mathrm{lit} / \mathrm{m}^{3}\right), \mathrm{Difficult}\left(80-\mathrm{I} 60 \mathrm{lit} / \mathrm{m}^{3}\right)$. Heartwood-sapwood boundary, well-defined (yes), poorly defined (poor), heartwood absent (no).

The ground glass end of one tube (110mm lengthx $25 \mathrm{~mm}$ width) was attached with non-toxic termite adhesive in the center of each wood block (Figure 1). Some wet sand (1:4 v/v water-sand ratio) was added to each tube, occupying at least two-thirds of the volume of the tube, and 250 termite workers, 5 soldiers and 5 nymphs were distributed. Test assemblies were keeping them in a culturing chamber with air circulation controlled at $22 \pm 2^{\circ} \mathrm{C}$ and $65 \pm 5 \%$ relative humidity for 8 weeks. Ten Pinus spp. samples were used to check the termite virulence. The tubs were unsealed at the end of the test period and the number of live termite workers, soldiers and nymphs were counted in order to determine the survival rate. Each wood block was also examined and visually rated using a standard rating system ${ }^{10}$ (Table 2). 
Table 2 Visual assessment rating of termite attack according to ENI I8 (2005)

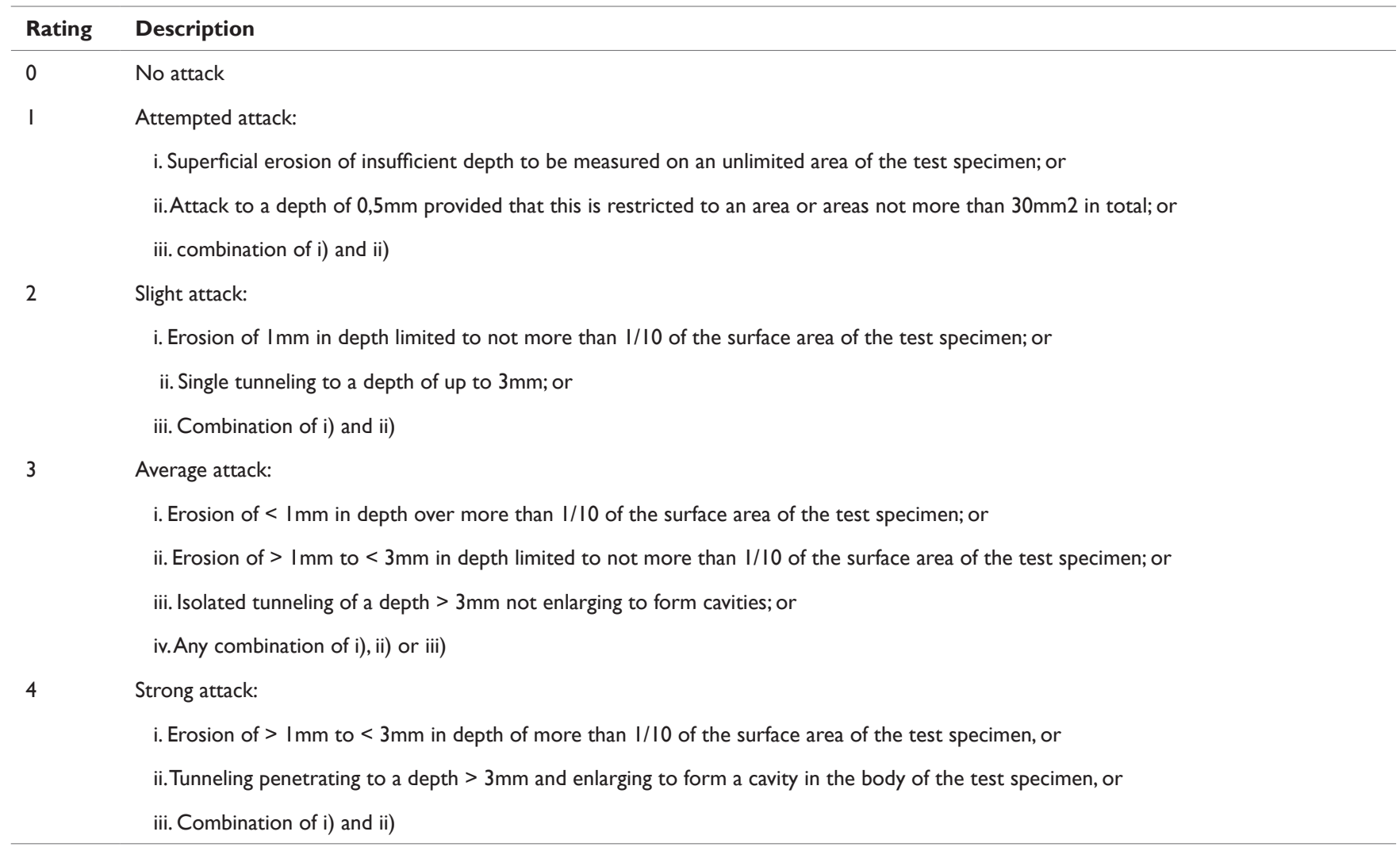

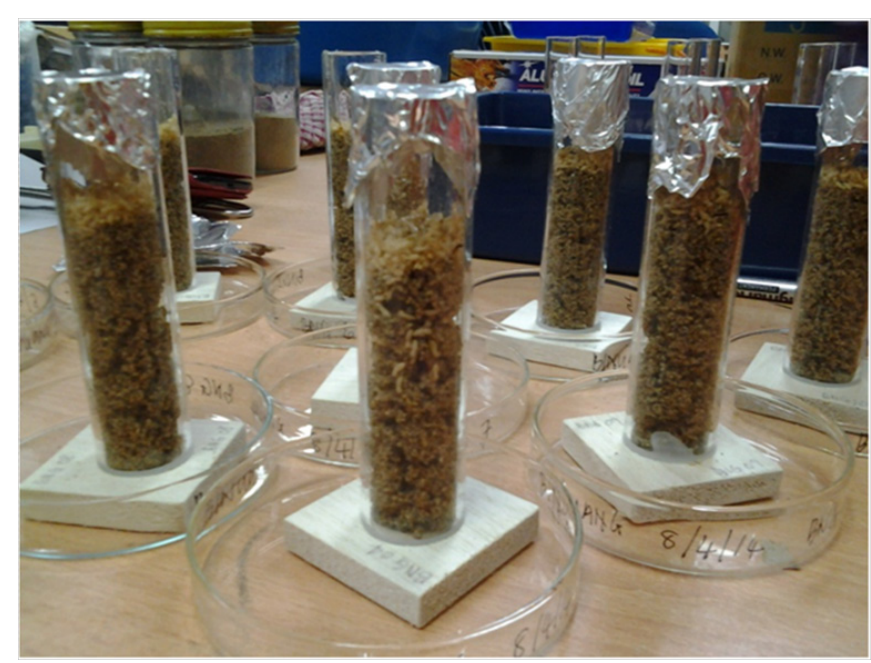

Figure I Arrangement of wood blocks for ENI I 8 (2005) test.

\section{Statistical analysis}

A suitable analysis of variance (ANOVA) was performed with wood consumption, degree of attack and the termite mortality rates resulted from the termite test as variables, in resistance to biodeterioration.

\section{Results and discussions}

\section{Wood density}

The result of density tests for the twenty two selected wood species shown in Table 3 revealed classification into three density classes:
C. Malaccensis, S. Borneensis, Dipterocarpus spp., D. Aromatica, Artocarpus sp., Canarium spp., F. fragrans, S. platyclados, $P$. velutinus, Syzigium sp. and M. indica were in high density class with values of $988,925,880,799,735,733,722,717,676,641$ and $639 \mathrm{~kg} / \mathrm{m}-3$, respectively; Parashorea spp., A. Mangium, Anisoptera sp. and C. Arborescens were in the medium density group had 575, 532, 523 and $497 \mathrm{~kg} / \mathrm{m}-3$, respectively, while Pinus spp., Heritiera spp., S. Parvifolia, Cinnamomum spp., D. Costulata, N. Cadamba and O. Sumatrana in the low density group $(474,470,466,457,378,359$ and $267 \mathrm{~kg} / \mathrm{m}-3$, respectively).

Table 3 Visual rating and durability classes of 22 Malaysian timbers and Pinus spp. according to ENII8 (2005)

\begin{tabular}{lll}
\hline Scientific name & Visual rating & Durability class \\
\hline A. Mangium & 4 & Susceptible \\
O. Sumatrana & 4 & Susceptible \\
C. Arborescens & 4 & Susceptible \\
Parashorea spp. & 3 & Susceptible \\
D. Costulata & 4 & Susceptible \\
D. Aromatica & 2 & Moderately durable \\
Canarium spp. & 2 & Moderately durable \\
C. Malaccencis & 1 & Durable \\
Syzigium sp. & 3 & Susceptible \\
Artocarpus sp. & 3 & Susceptible \\
N. Cadamba & 4 & Susceptible \\
\hline
\end{tabular}


Table Continued....

\begin{tabular}{lll}
\hline Scientific name & Visual rating & Durability class \\
\hline Dipterocarpus spp. & 3 & Susceptible \\
S. Borneensis & 2 & Moderately durable \\
M. indica & 4 & Susceptible \\
Cinnamomum spp. & I & Durable \\
Heritiera spp. & 4 & Susceptible \\
S. Platyclados & 4 & Susceptible \\
S. Parvifolia & 4 & Susceptible \\
Anisoptera sp. & 3 & Susceptible \\
P.Velutinus & 4 & Susceptible \\
E. Malaccense & 4 & Susceptible \\
F. Fragrans & 4 & Susceptible \\
Pinus spp. & 4 & Susceptible
\end{tabular}

Notes Mean ( $( \pm \mathrm{SD})$ of 10 replicates for each species. $0=$ no attack, I =attempted attack, 2 =slight attack, 3 =average attack and4 =strong attack

\section{Visual rating}

Figure 2 gives the general appearances of twenty two Malaysian timber species specimens after the termite standard test. It is apparent that A. Mangium, O. Sumatrana, C. Arborescens, D. Costulata, N. Cadamba, M. Indica, Heritiera spp., S. Platyclados, S. Parvifolia, P. Velutinus, E. Malaccense and F. Fragrans were the species that intensely attacked (visual rating of 4 ) which classified as susceptible timbers. Another four timber species (Parashorea spp., Syzigium sp., Artocarpus sp. and Anisoptera sp.) also classified as susceptible timbers, but with a visual rating of 3 which means that there is a potential for wood is classified under a durable medium if the age of the tree is older. ${ }^{12}$ D. Aromatica, Canarium spp. and S. Borneensis were moderately attacked, while C. Malaccencis and Cinnamomum spp. be almost untouched. Pinus spp. proved to be completely susceptible to subterranean termites (all 10 replicates had 4 visual rating after eight weeks exposure, Table 4). The same findings were also observed by $\mathrm{Tho}^{13}$ on plantation-grown exotic softwood (P.Caribaea) from Malaysia and Indonesia against $C$. Curvignathus, P. Insularis by Mohd Dahlan \& Tam $^{14}$ and P. Sylvestris against C. Formosanus in the laboratory by Grace et al. ${ }^{15}$

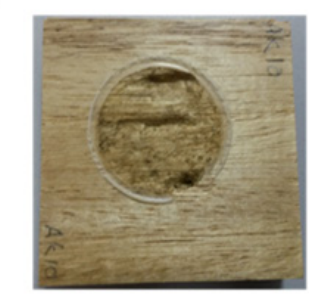

Acacia mangium (4)

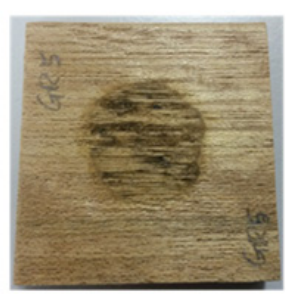

Parashorea spp. (3)

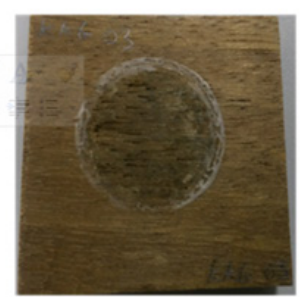

Cynometra malaccensis (1)

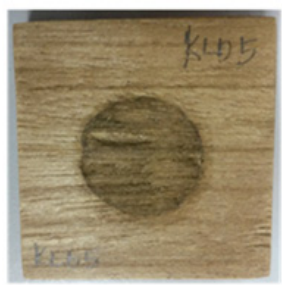

Artocarpus spp. (3)

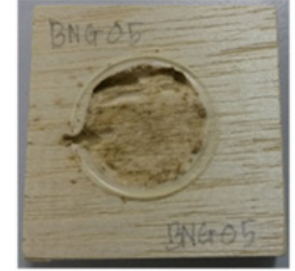

Octomeles sumatrana (4)

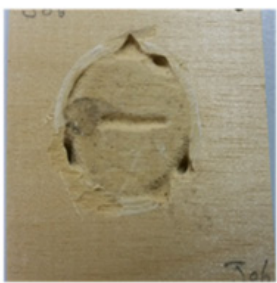

Dyera costulata (4)

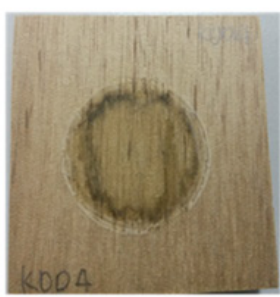

Canarium sp. (2)

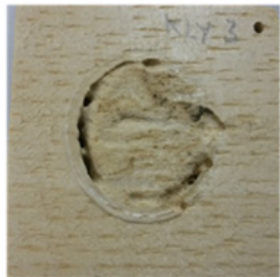

Neolamarckia cadamba (4)

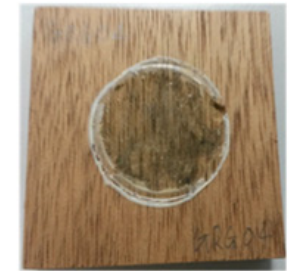

Cratoxylum arborescens (4)

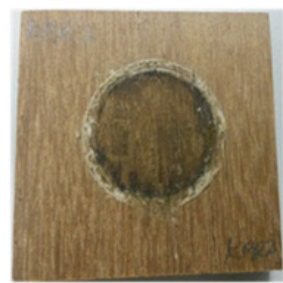

Drybalanops aromatica (2)

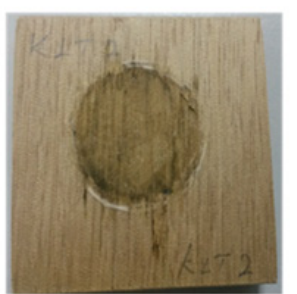

Syzigium sp. (3)

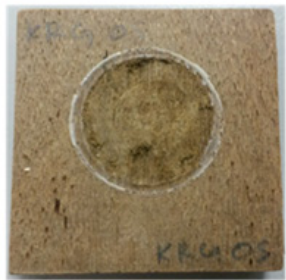

Dipterocarpus spp. (3) 


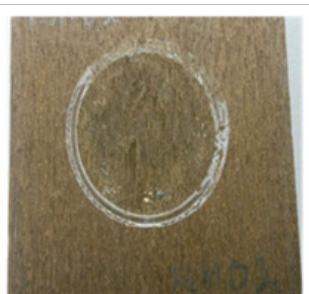

Scorodocarpus borneensis (2)

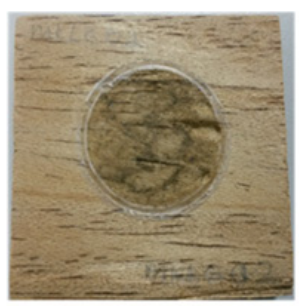

Heritiera spp. (4)

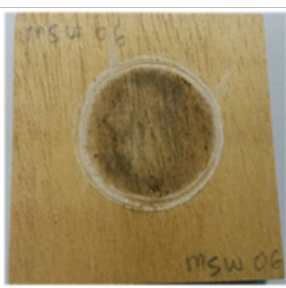

Anisoptera sp. (3)

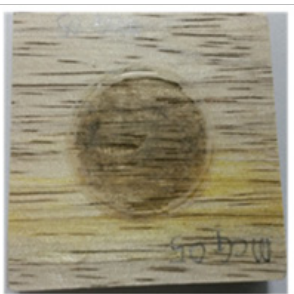

Mangifera indica (4)

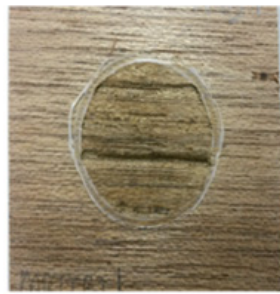

Shorea platyclados (4)

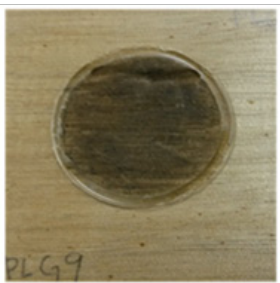

Pentaspadon velutinus (4)

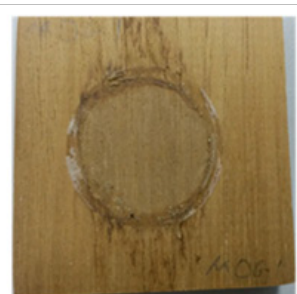

Cinnamomum spp. (1)

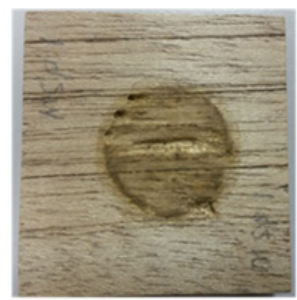

Shorea parvifolia (4)

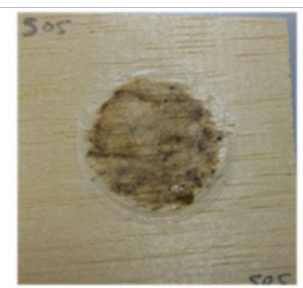

Endospermum malaccense (4)

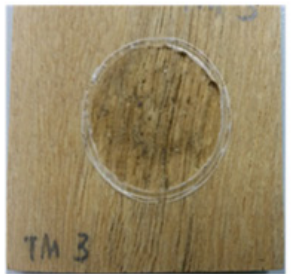

Fagraea fragrans (4)

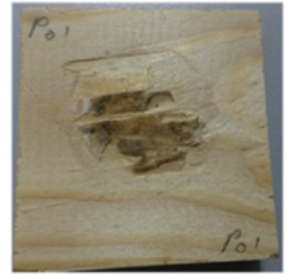

Pinus spp. (4)

Figure 2 Examples of attacked area of 22 Malaysian timber species and Pinus spp. exposed to C. Curvignathus according to ENI I 8:2005. Numbers in paranthesis are visual assessment rating assigned to the sample.

Table 4 Density and wood consumption of 22 Malaysian timbers and Pinus sp. against C. Curvignathus

\begin{tabular}{llll}
\hline Scientific name & Density range $\left(\mathbf{k g} / \mathbf{m}^{-3}\right)$ & Wood consumption(\%) & Termite mortality(\%) \\
\hline A. Mangium & $513-561$ & $11.71(0.17)^{\mathrm{a}}$ & 100 \\
O. Sumatrana & $244-970$ & $8.22(1.35)^{\mathrm{b}}$ & 100 \\
C.Arborescens & $461-518$ & $3.16(0.19)^{\mathrm{f}}$ & 100 \\
Parashorea spp. & $549-61 \mathrm{I}$ & $8.79(0.79)^{\mathrm{b}}$ & 100 \\
D. Costulata & $342-439$ & $11.17(1.17)^{\mathrm{a}}$ & 100 \\
D. Aromatica & $777-830$ & $2.42(0.83)^{\mathrm{f}}$ & 100 \\
Canarium spp. & $693-746$ & $1.66(0.34)^{\mathrm{g}}$ & 100 \\
C. Malaccencis & $978-1008$ & $0.47(0.15)^{\mathrm{i}}$ & 100 \\
Syzigium sp. & $597-667$ & $3.51(1.26)^{\mathrm{f}}$ & 100 \\
Artocarpus sp. & $727-75 \mathrm{I}$ & $6.96(0.09)^{\mathrm{d}}$ & 100 \\
N. Cadamba & $350-364$ & $9.25(2.18)^{\mathrm{bc}}$ & 100 \\
Dipterocarpus spp. & $763-916$ & $8.90(0.83)^{\mathrm{b}}$ & 100 \\
\hline
\end{tabular}

Citation: Roszaini K, Salmiah U, Rahim S, et al. Qualitative and quantitative determination of resistance of twenty two Malaysian commercial timbers through subterranean termite feeding behavior. Forest Res Eng Int J. 20I7; I(2):52-60. DOI: I0.15406/freij.2017.01.00008 
Table Continued..

\begin{tabular}{llll}
\hline Scientific name & Density range $\left(\mathbf{k g} / \mathbf{m}^{-3}\right)$ & Wood consumption(\%) & Termite mortality(\%) \\
\hline S. Borneensis & $915-934$ & $0.27(0.10)^{\mathrm{j}}$ & 100 \\
M. indica & $632-646$ & $6.54(0.88)^{\mathrm{e}}$ & 100 \\
Cinnamomum spp. & $432-469$ & $0.98(0.4 \mathrm{I})^{\mathrm{h}}$ & 100 \\
Heritiera spp. & $463-484$ & $9.44(0.21)^{\mathrm{b}}$ & 100 \\
S. Platyclados & $681-758$ & $7.47(0.17)^{\mathrm{c}}$ & 100 \\
S. Parvifolia & $457-479$ & $7.59(0.67)^{\mathrm{c}}$ & 100 \\
Anisoptera sp. & $467-557$ & $3.13(0.73)^{\mathrm{f}}$ & 100 \\
P.Velutinus & $609-736$ & $6.33(0.3 \mathrm{I})^{\mathrm{e}}$ & 100 \\
E. Malaccense & $347-368$ & $8.11(1.60)^{\mathrm{bc}}$ & 100 \\
F. Fragrans & $700-743$ & $4.25(0.63)^{\mathrm{f}}$ & 100 \\
Pinus spp. & $465-504$ & $11.38(0.55)^{\mathrm{a}}$ & 100 \\
\hline
\end{tabular}

Notes Mean $( \pm S D)$ of 10 replicates for each species. Percentage values followed by the same letter are not significantly different in the same group at the 0.05 level of probability

\section{Weight loss or wood consumption}

Generally, C. Curvignathus were unable to survive for the full 8 weeks of exposure on all timber tested. However, the woods were damaged before the termites died and the damaged varied considerably among these timber species (Table 4). Analysis of variance also revealed the mean difference was significantly different from one another $(\mathrm{F}$, 7.859; d.f. $3: 8: 11 ; \mathrm{P}<0.001)$. The termite choice test showed that among the twenty two wood species tested, A. Mangium (11.71\%) and D. Costulata $(11.17 \%)$ had higher average wood consumption $(>10 \%)$ followed by another eleven timber species; Heritiera spp. $=9.44 \%$, N. Cadamba $=9.25 \%$, Dipterocarpus spp $=8.90 \%$, Parashorea spp. $=8.79 \%, O$. Sumatrana $=8.22 \%$, E. Malaccense $=8.11 \%, S$. Parvifolia $=7.59 \%$, S. Platyclados $=7.44 \%$, Artocarpus $\mathrm{sp} .=6.96 \%, M$. Indica $=6.54 \%$ and $P$. Velutinus $=6.33 \%$. Nine wood species had less than $5 \%$ of weight loss; F. Fragrans (4.25\%), Syzigium sp.(3.51\%), C. Arborescens (3.16\%), Anisoptera sp. (3.13\%), D. Aromatica (2.42\%), Canarium spp. (1.66\%), Cinnamomum spp. (0.98\%), C. Malaccensis $(0.47 \%)$ and S. Borneensis $(0.27 \%)$. Pinus spp. control samples were strongly attacked by the termite species with an attack of 4 (visual rating) and $11.38 \%$ of weight loss. Thus, it can be deduced that $A$. Mangium and D. Costulata constituted the termite's first and second choices, respectively, while C. Malaccensis and S. Borneensis were not preferred (distasteful) by the termites since it was left alone by the termites after an exploratory nibbling etched the wood surface damaged during the 8 weeks exposure. On the other hand, Tamashiro et al. ${ }^{16}$ stated that weight loss or wood consumption less than $3 \%$ would be considered as cosmetic damage which unlikely to create a structural hazard, but additional field evaluations are needed to determine the treatment requirements for timbers. Meanwhile, the first third teen timber species were easily degraded despite the toxicity of some of the resinous extractives against termites, ${ }^{15}$ the content of which may be insufficient to override the presence of feeding stimulant chemicals in the wood. ${ }^{17}$ Along with wood extractive, chemical components such as cellulose, lignin and total phenolic content of wood showed influence on the rate of degradation. ${ }^{18}$ The higher cellulose content, the less resistance to termite attacked ${ }^{19}$ and the higher lignin and total phenolic content, the more resistance of the wood against termite attack. ${ }^{20}$

On the other hand, C. Malaccensis and Cinnamomum spp. have proved in this test to be highly resistant against $C$. Curvignathus although these two species were found to be susceptible using other standard methods. ${ }^{21,22}$ Meanwhile, these termites are fond to $A$. Mangium, D. Costulata and Pinus spp. based on the high percentage of wood consumption (more than $10 \%)(11.71 \%, 11.17 \%$ and $11.38 \%$, respectively) with all visual rating are 4 . Resistance situation can be meaning that the death of termites was caused by starvation or a volatile substance in the wood while susceptible means no repellent or insufficient repellent to prevent substantial feeding for $^{23}$ but then, different feeding on different timber species may be due to some differences in chemical composition. For example, a higher quantity of carbohydrates (especially starch content) can make the timbers relatively more susceptible to insect attack..$^{24-26}$

In the case of $C$. Arborescens, D. Aromatic, Canarium spp., Syzigium sp., Anisoptera sp. and F. Fragrans that fell under moderately durable and susceptible, but with a lower percentage of wood consumption $(1.66 \%$ to $4.25 \%)$ could be due to the unequally distributed of resistant components present in the part of the plant and there is a need to further investigate the nature of the compounds having anti-termitic properties within these woods. As mentioned by Aihetasham \& Iqbal, ${ }^{27}$ the occurrence of organic chemicals such as phenol, quinines, terpenoids and high concentration of lignin may also affect the areas where feeding takes place.

\section{Termite mortality}

Interestingly, the standard test revealed that the termite survival rate is not necessarily related to the durability of the wood species due to the same $(100 \%)$ average percentage of termite death was observed in all test containers. From this, it might be inferred that although C. Malaccensis and Cinnamomum spp. be classified as durable against termites, it can be attacked. In fact, both the termite standard and choice tests showed signs of slight attacks. This confirmed the assertion that no wood is completely immune from the attack of termites, only the degree of resistance is varies. ${ }^{28,29}$

\section{Correlation between wood density and wood consumption}

Even though past studies ${ }^{30}$ that densities influence the termite's ability to fragment the wood mechanically with its mandibles, Figure 3 , show that there was a poor or weak correlation $\left(\mathrm{R}^{2}=0.322\right)$ between density and wood consumption which revealing that with 
the increasing of wood density values, it is not sure that the wood consumption will decrease. Same studies done by Roszaini and Hale (2012) on 12 Malaysian commercial wood species also found the similar trend even though they used other standard methods, ASTM D3345-74 (1988). Peralta et al. ${ }^{31}$ on their study under field conditions also did not find a strong correlation between wood density and termite resistance of different forest species. So the use of density factor alone is not sufficient to determine the durability of Malaysia timber which means that density alone cannot confer durability of timber. Other factors such as the presence of toxic extractives should be taken into consideration ${ }^{32}$ because in no-choice laboratories tests, where termites have to feed on the single wood species presented to them, an accumulation of wood toxins in the confined environment could lead to high mortality. ${ }^{33}$

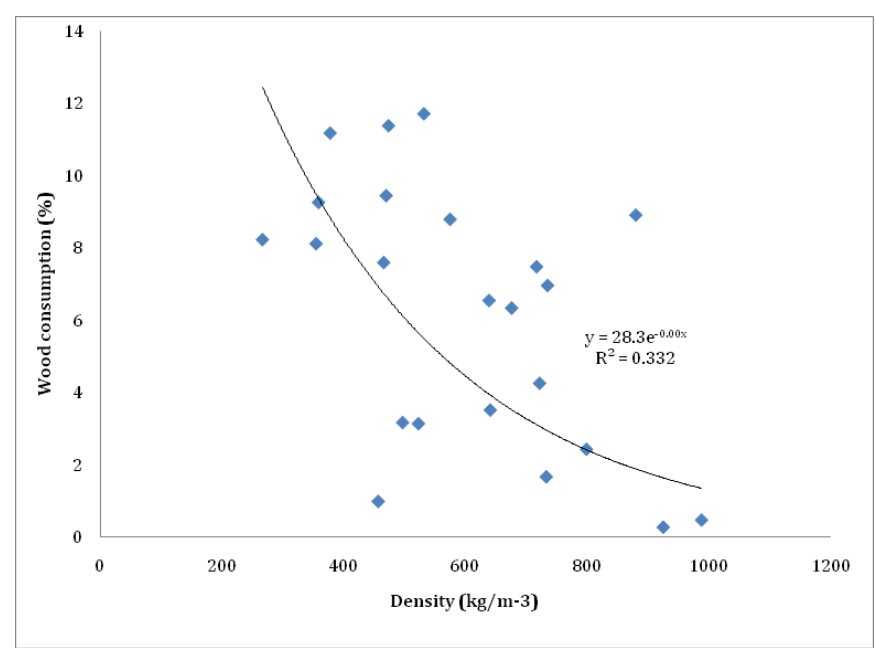

Figure 3 Correlation between wood density and wood consumption for 22 Malaysian commercial timber species after 8 weeks laboratory termite test.

\section{Correlation between wood density and visual rating}

A linear regression analysis (Figure 4) was performed to establish a correlation between wood density and visual rating for all timber species. As the wood density increased, the visual rating decreased (more resistance). However, results show that there was a weak correlation $\left(\mathrm{R}^{2}=0.27\right)$ between both variables. On the other hand, study by Owoyemi et al. ${ }^{30}$ shows a strong and positive correlation $\left(\mathrm{R}^{2}=0.83\right)$ existed between visual rating and wood density of ten selected Nigerian wood species against Macrotermes sybhylinus (subterranean termites). They concluded that higher wood density species tend to more resistance than medium and low density species.

\section{Correlation between wood consumption and visual rating}

The regression equation of correlation analysis between wood consumption and visual rating (samples damage) is plotted in Figure 5 . The relationships between both variables for twenty two Malaysian commercial wood species were strong $\left(\mathrm{R}^{2}=0.6789\right)$. The results show that when the percentage of wood consumption increased, the visual rating increased (less termite resistance). Wong et al. ${ }^{33}$ reported that there was a tendency towards higher mass loss or reduced termite mortality to correspond with the lower visual ratings (low termite resistance) of 5 lesser-s known species of Malaysian hardwoods: kekatong (Cynometra sp.), kelat (Eugenia spp.), mempening (Lithocarpus spp.), perah (Elateriospermum tapos) and pauh kijang
(Irvingia malayana) against Coptotermes curvignathus. In another situation, Lee et al..$^{34}$ found a strong correlation between these two variables for treated samples [zinc borate $\left(\mathrm{R}^{2}=0.94\right)$ and calcium borate $\left.\left(\mathrm{R}^{2}=0.82\right)\right] \cdot{ }^{35-39}$

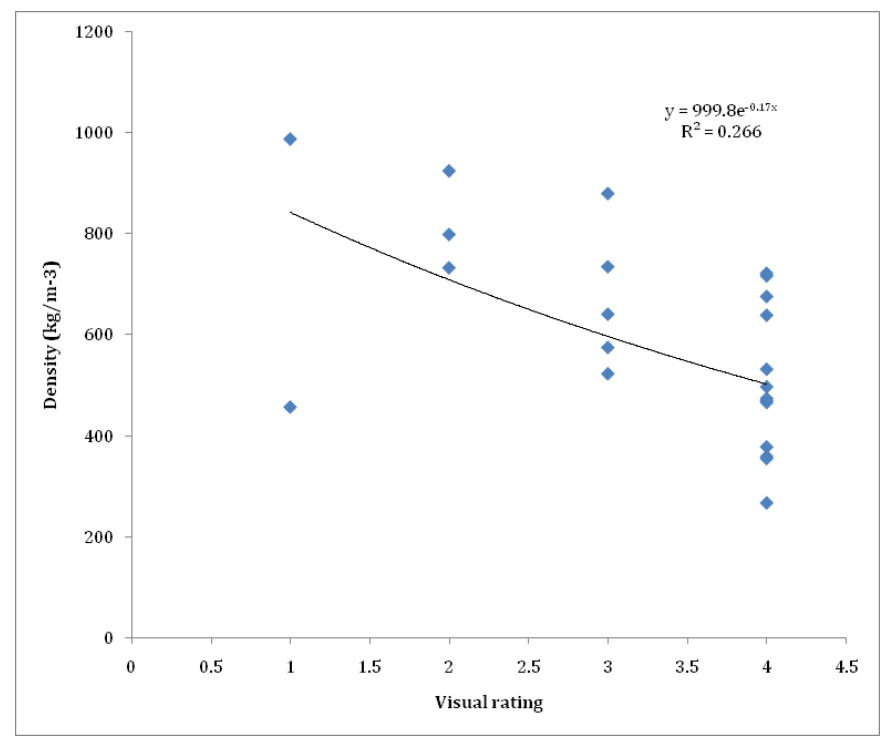

Figure 4 Correlation between wood density and visual rating for 22 Malaysian commercial timber species after 8 weeks laboratory termite test.Visual rating - Damage rating based on I-4 scale with 4 denoting the most damage.

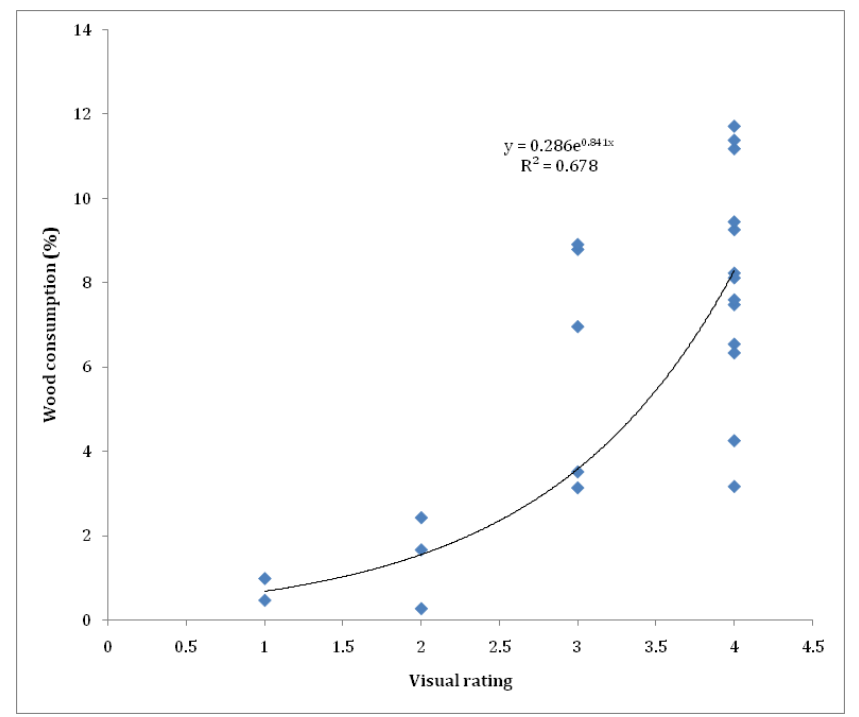

Figure 5 Correlation between wood consumption and visual rating for 22 Malaysian commercial timber species after an 8 weeks laboratory termite test. Visual rating - Damage rating based on I-4 scale with 4 denoting the most damage.

\section{Conclusion}

The natural durability of 22 Malaysian timber species was evaluated based on laboratory test. A. Mangium, O. sumatrana, C. Arborescens, D. Costulata, N. Cadamba, M. Indica, Heritiera spp., S. Platyclados, S. Parvifolia, P. Velutinus, E. Malaccense, F. Fragrans and Pinus spp. be all susceptible to termites. Parashorea spp., Syzigium sp., Artocarpus sp. and Anisoptera sp. be also rating as susceptible but with durability class of 3. D. Aromatica, Canarium spp. and $S$. Borneensis be moderately attacked while $C$. Malaccencis and 
Cinnamomums spp. be durable against termites. Certain treatments are needed to susceptible timber species in order to ensure a longer service life of the wood.

\section{Acknowledgements}

We would like to thank the Forestry Department of Malaysia (JPSM), Malaysian Timber Industry Board (MTIB), Malaysian Timber Council (MTC), Malaysian Wood Industries Association (MWIA), Malaysian Panel-Products Manufacturers' Association (MPMA), Sabah Timber Industries Association (STIA) and Sarawak Timber Industry Development Corporation (STIDC), the departments involved directly or indirectly in this project for their contributions and cooperation in this project. Funding for this research was fully provided by Tabung Pembangunan Industri Kayu Kayan Malaysia (TPIKM).

\section{Conflict of interest}

The author declares that there is no conflict of interest.

\section{References}

1. BS EN 350-1. Durability of wood and wood-based product- Natural durability of solid wood-Part2: Guide to natural durability and treatability of selected wood species of importance in Europe. Brussels, Belgium European Committee for Standardization; 1994. p. 1-18.

2. Eaton RA, Hale MD. Wood: Decay, pests and protection. London, New York: Chapman and Hall; 1993.

3. American Society for Testing and Materials (ASTM). Standard method of accelerated laboratory testing of natural decay resistance of wood (D2017). USA: In ASTM Annual Book of Standards. West Conshohocken: Wood; 1993;4(9):344-348.

4. ASTM (American Society for Testing and Materials). Standard test method of laboratory evaluation of wood and other cellulosic materials for resistance to termites (D3345-74). In: ASTM Annual Book of Standards. West Conshohocken, USA: Wood; 1988;4(10):430-432.

5. Domone P, Illston J. Construction materials: Their nature and behavior. 4th ed. London \& New York: CRC Press; 2010.

6. Schultz TP, Harms WB, Fisher TH, et al. Durability of angiosperm heartwood: The important of extractives. Holzforschung. 1995;49(1):29-34.

7. Scheffer TC, Cowling EB. Natural resistance of wood to microbial deterioration. Annual Review Phytopathology. 1966;4:147-168.

8. Taylor AM, Gartner BL, Morrell JJ. Heartwood formation and natural durability-a review. Wood Fiber Science. 2002;34(4):587-611.

9. Silva CA, Monteiro MBB, Brazolin S, et al. Biodeterioration of brazilwood Caesalpinia echinata Lam. (Leguminosae-Caesalpinioideae) by rot fungi and termites. International Biodeterioration and Biodegradation. 2007;60(4):285-292.

10. EN 118. Wood preservatives, determination of preventive action against Reticulitermes species (European termites) (laboratory method). Washington DC, USA: USDA Forest Service; 2005.

11. Roszaini K, Rafeadah R, Mohd Dahlan J. Durability of Malaysian timbers against the Asian subterranean termite Coptotermes gestroi Wasmann. Journal Institute of Wood Science. 2009;19:16-21.

12. Nagayeni HC, Vijayalakshmi G, Venmalar D, et al. Durability of timber of Grevillea robusta (A. Cunn. Ex R. Br.) at different ages, grown in dry and wet regions of Karnataka. Journal of the Indian Academy of Wood Science. 2011;8(2):173-176.

13. Tho YP. The termite problem in plantation forestry in Peninsular Malaysia. Malaysian Forester. 1975;37(4):278-283.
14. Mohd Dahlan J, Tam MK. Natural durability of Malaysian timbers. Timber Trade Leaflet No. 28. Malaysian Timber Industry Board \& Forest Research Institute Malaysia. 1987.

15. Grace JK, Wong AHH, Tome CHM. Termite resistance of Malaysian and exotic woods with plantation potential: Laboratory evaluation. The International Research Group on Wood Preservation. 1998. p. 1-10.

16. Tamashiro M, Yamamoto RT, Grace JK. Treatment of Douglas fir heartwood with disodium octaborate tetrahydrate (TimBor) to prevent attack by the Formosan subterranean termite. The International Research Group on Wood Preservation. 1991.

17. Grace JC. The challenge of wood destroying insects. Proceeding of the Canadian Wood Preservation Association. 1987;7:3-12.

18. Shanbag RR, Sundararaj R. Imported wood decomposition by termites in different agro-eco zones of India. International Biodeterioration and Biodegradation. 2013;85:16-22.

19. La Fage JP, Nutting WL. Nutrient dynamics of termites. In: Brian MV, editor. Production ecology of ants and termites. London: Cambridge University Press; 1978.

20. Syafii W, Samejima M, Yoshimoto T. The role of extractives in decay resistance Ulin wood (Eusideroxylon zwageri T. Et. B.). Bulletin of Tokyo University and Forestry. 1988;77:1-8.

21. Chudnoff M. Tropical timbers of the world. Agricultural Handbook 607, Germany: Publishing House Kessel; 1984. 1-19p.

22. Roszaini K, Hale MD. Comparative termite resistance of 12 Malaysian timber species in laboratory tests. Holzforschung. 2912;66:127-130.

23. Bultman JD, Beal RH, Ampong FFK. Natural resistance of some tropical African woods to Coptotermes formosanus Shiraki. Forest Products Journal. 1979;29(6):46-51.

24. Beeson CFC. Ecology and control of forest insects of India and neighbouring countries. Dehra Dun, India: Varsent Press; 1941.

25. Roonwal ML, Thapa RS. Experiments on fresh water seasoning (water immersion) of the three species of Indian timbers to provide anti-insect protection. Indian Forester. 1960;10(1):41.

26. Sulthoni A. A simple and cheap method of bamboo preservation. Proceeding of the 3rd International Bamboo Workshop. 1988:209-211.

27. Aihetasham A, Iqbal S. Feeding preferences of Microcerotermes championi (Snyder) for different wooden blocks dried at different temperature under forced and choice feeding conditions in laboratory and field. Pakistan Journal of Zoology. 2001;44:1137-1144.

28. Daniel RS, Susan CJ, Brain TF. Biology of subterranean termites in the Eastern United States Bulletin. 2009;120:1-16.

29. Mike P. Protecting your home against termites department of Entomology. Kentucky: University of Kentucky College; 2010. p. 1-2.

30. Owoyemi JM, Olaniran OS, Aliyu DI. Effect of density on the natural resistance of ten selected Nigerian wood species to subterranean termites. Pro Ligno; 2014;9(1):32-40.

31. Peralta RCG, Menezes EB, Carvlho AG, et al. Wood consumption rate of forest by subterranean termites (Isoptera) under field conditions. Revista Arvore. 2004;28:1-7.

32. Rowell RM. Handbook of wood chemistry and wood composites. Rowell RM ed. USA: CRC Press; 2005.

33. Wong AAH, Cheok KS, Grace JK. Laboratory evaluation of termite resistance of five lesser-known Malaysian hardwoods used for roof and ceiling construction. The International Research Group on Wood Preservation. 2001. p. 1-2.

34. Lee S, Wu Q, Ramsay SW. Formosan subterranean termite resistance of borate-modified strandboard manufactured from southern wood species: A laboratory trial. Wood Fiber Science. 2004;36(1):107-118. 
35. Wong, TM. A dictionary of Malaysian timbers. (Lim SC, Chung RCK revision), Malayan Forest Records No. 30. Kuala Lumpur, Malaysia: Forest Research Institute Malaysia; 1982

36. Anonymous. The Malaysian grading rules for sawn hardwood timber. 2nd ed. Malaysia: Malaysian Timber Industry Board; 1984.

37. Wong AHH, Grace JK, Kirton LG. Termite resistance of Malaysian and exotic woods with plantation potential: field evaluation. The International Research Group on Wood Preservation. 1998.
38. Gan KS, Choo KT, Lim SC. Timber Notes-Medium Hardwoods I (Kapur, Kasai, Kelat, Keledang, Kempas). Timber Technology Bulletin. 1999. p. $1-8$.

39. Anonymous. Malaysian Standard MS 360:1991. Specification for treatment of timber with copper/chrome/arsenic preservatives. Malaysia: Standards and Industrial Research Institute of Malaysia (SIRIM); 1991. 